\title{
Impact of distributed power generation at the customer
}

\author{
Marius Salen ${ }^{1} \quad$ Dietmar Winkler $^{2}$ \\ ${ }^{1}$ University of South-Eastern Norway, salen 93egmail .com \\ ${ }^{2}$ University of South-Eastern Norway, dietmar.winkler@usn. no
}

\begin{abstract}
In collaboration with the Distributed System Operator (DSO) at Hvaler which is Norgesnett, a weak grid is simulated in NETBAS. The aim with the simulation is to study the impact clouds have on the production at the solar panels since the production drops locally at the customers from passing clouds. Also, the impact this has on the DSO with the requirements given from $\S 3.4$ in the Norwegian Directive on Quality of supply (FoL) regarding $\Delta U_{\text {stationary }}$ are considered. The simulations are conducted with different scenarios which illustrate the power production in the solar panels when cloudy. In collaboration with the Norwegian Meteorological Institute (MET Norway) solar data is used to get a more realistic picture of the sun condition at Hvaler and the corresponding scenarios. The main findings are that the passing clouds had a large impact on the voltage drop at the customers simulated in the weak grid at Søndre Sandøy. Also the objects at Søndre Sandøy without solar panels are affected by the clouds reducing the power output from the objects with solar panels. As a result, both of the objects with and without solar panels exceeded the requirement given from FoL $\S 3.4$ in some of the scenarios. The conclusion is that clouds had a significant impact on the customers simulated at the weak grid at Hvaler, resulting in a voltage drop which gives challenges for the DSO regarding FoL.
\end{abstract}

Keywords: distributed power generation, solar production, FoL, DSO, prosumer

\section{Introduction}

Hvaler is an island community outside Fredrikstad, with a population of 4400 inhabitants. In summer, the population of Hvaler increases to about 30000 since Hvaler is a popular holiday resort with many summer residents (Wikipedia 2019). Such an increase in population can lead to a rise of power consumption resulting in power peaks, especially during the summer season.

\subsection{Previous work and motivation}

With passing clouds on solar panels and its impact regarding the voltage drop, there has been done previous work at the field. From the paper "Passing-cloud Effects of Solar Photovoltaic System on Distribution Network Voltages" (Cheiw Yun Lau, Chin Kim Gan, Chin Ho Tie, Kyairul Azmi Baharin, Mohamad Fani Sulaima 2015), the conclu- sion were that a voltage drop may occur when clouds are passing and reducing the generation from the solar panels due to the cumulus sky. That paper was comparing passing clouds on a sunny day with a cloudy day. In this paper however we investigate passing clouds on a sunny day on a weak grid concerning the voltage drop.

In 2014 a Master's Thesis in collaboration with Norgesnett was conducted (Ellefsen 2014). One of the main objectives from that thesis was to study the risk of overvoltages coming from solar panels potentially installed in the distribution network at Hvaler. Also that research used Søndre Sand $\varnothing \mathrm{y}$ as a test area for the simulations. The highest overvoltages occurred in June according to the conclusion.

From this, the motivation for this paper is to present how solar panels at the customers in Søndre Sandøy get affected by the clouds which are reducing the production on a specific day in June. Also, a goal with the paper is to get a better understanding on how the clouds reduce the power output from the solar panels leading to a voltage drop at the customer.

\subsection{Problem description}

This paper is investigating a part of Norgesnett's distribution network on Hvaler, where the voltage drop locally at the customers is studied. This is caused by the reduction in the solar panels from the passing clouds. Further, similar remote areas like Hvaler with distributed generation may benefit from this work.

The simulation is performed in collaboration with Norgesnett, and the software NETBAS(POWEL 2018) is used. The area simulated is in Hvaler (Norway), in a collaboration with the local DSO. After discussions with Norgesnett it was decided to simulate two areas of the distribution network, a robust and weak grid. NETBAS is used to study the behaviour of the two areas after passing clouds reduce the production from the installed solar panels at the customers. The customers will be referred to as objects throughout the paper. The passing clouds can lead to a voltage drop which can be problematic for the DSO. The results from the simulations are compared with the requirements given in FoL $\$ 3.4$, regarding $\Delta U_{\text {stationary }}$. Since the Master's Thesis revealed most challenges at the weak grid at Søndre Sandøy this will be focus area in this paper (Marius Salen 2019). 


\subsection{Limitations}

- From $\$ 3.4$ in FoL $\Delta U_{\text {stationary }}$ is considered and $\Delta U_{\max }$ is not.

- During the sun minutes, no changes from sun to clouds are taken into consideration. Moreover, when passing clouds occur, this change from sun to cloud is set to each third minute. This is explained in more detail at Section 3.1

- When clouds reduce the power generated locally from the solar panels this occur at the same time for all objects in the scenarios.

\section{Background}

\subsection{Active distribution system}

When a customer has a surplus of power an alternative to storage is to feed the power back to the grid, which is called prosumers (Wilson Rickerson 2014). Prosumers which are feeding the power back into the grid makes an impact due to a voltage rise in the grid. In Figure 1 the voltage rise at the distribution network can be expressed by Equation (1), where the voltage drop is increasing when $P$ and $Q$ are increasing.

$$
\Delta U=U_{2}-U_{1}=\frac{P_{2} \cdot R+Q_{2} \cdot X}{U_{2}}
$$

In Equation (1), $U_{2}$ represents the direction where the power flow is reversed. Also, the voltage at the point of connection of the generator will increase to a higher value than the sending end voltage, visualised in Figure 1 (M.A. Mahmud, M.J. Hossain, H.R. Pota 2011). When a prosumer has surplus power this will contribute to a higher voltage. Furthermore, $I_{2}$ will have negative value and $U_{2}$ will be greater than $U_{1}$. When distributed generation (DG) is connected as shown in Figure 1 the system is not a passive system, but rather an active system.

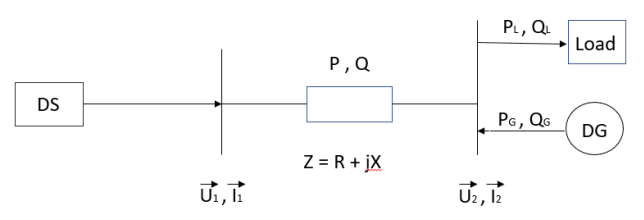

Figure 1. An active distribution system with DG at the customer.

\section{2 $\mathrm{X} / \mathrm{R}$ - Ratio in the distribution network}

Figure 2 is from (Christian Rendall Olsen 2018) and shows how the reactance $X$ gets smaller from the power grid towards the object. On the other hand, the resistance $R$ increases from the power grid towards the object. In a distribution network, the power factor (PF), $\cos \theta$ is high with typical values of 0.98 found from NETBAS. This

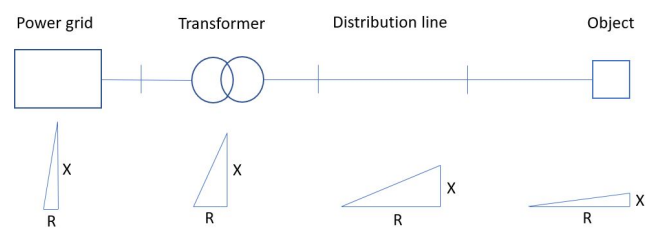

Figure 2. X-R ratio for a typical distribution network. (Christian Rendall Olsen 2018).

gives $R \gg X$. From this, Equation (1) can be rewritten into Equation (2) because the $X Q$ term is neglected:

$$
\triangle U=\frac{R \cdot P}{U_{2}}
$$

The $\cos \theta$ indicates the ratio between active and apparent power, visualised by the power triangle as seen in Figure 3. When simulated in NETBAS the PF at the objects are between 0.975 and 0.985 which is a large PF, resulting in a low contribution of reactive power. At the objects in the test area there are almost purely resistive loads. Typical equipment which contributes to increasing the reactive power are larger motors which include an inductor. Such equipment is not present at Søndre Sandøy.

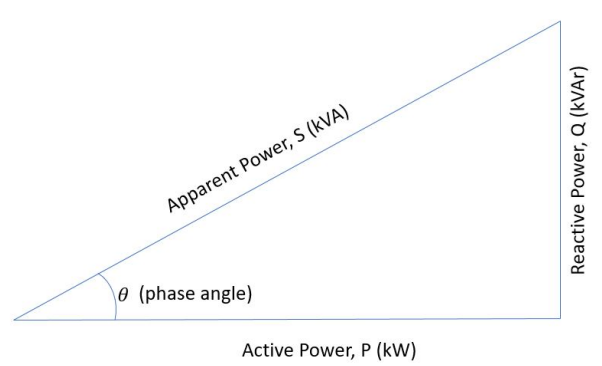

Figure 3. The power triangle.

\section{Method}

The test area is simulated to see if the requirement of $\Delta U_{\text {stationary }}$ from $\S 3.4$ in FoL are held. These requirements are according to Table 1 which is explained in detail at Section 2.4.

An important topic in this paper is the voltage variations where FoL has requirements that need to be met. These requirements are found in FoL, $\S 3.4$ and states: (Lovdata 2004)

"The Norwegian water resources and energy directorate (NVE) may order those who are covered by this regulations to implement measures to reduce the scope or consequences of voltage dips and voltage swells.

DSOs shall ensure that voltage swells, voltage dips and Rapid Voltage Changes (RVC) do not exceed the following limit values in the point of connection with the respec- 
tive nominal voltage level, $U_{N}$, for the respective time interval."

The purpose of these regulations is to ensure that the customer only experience a limited number of voltage swells, voltage dips and RVC (Lovdata 2004).

In a network with $230 \mathrm{~V}$ the RVC are within the interval of $207-253 \mathrm{~V}$, which is a margin of $\pm 10 \%$ from $230 \mathrm{~V}$. However, at any point if the voltage drops under $207 \mathrm{~V}$ it is categorised as a voltage dip, or if it exceeds $253 \mathrm{~V}$, as a voltage swell. In low- and high voltage distribution network with voltages between $230 \mathrm{~V}-35 \mathrm{kV}$ then 24 voltage variations within a 24 hours period are allowed (Lovdata 2004).

Table 1. $\Delta U_{\text {stationary }}$ can exceed the limit of $3 \%$ from FoL at a maximum of 24 times in a 24 -hours period.

\begin{tabular}{|l|c|}
\hline $\begin{array}{l}\text { Voltage swells, voltage dips } \\
\text { and rapid voltage changes }\end{array}$ & $\begin{array}{l}\text { Max number pr floating } \\
\text { 24-hours period }\end{array}$ \\
\hline & $0.23 \mathrm{kV} \leq U_{N} \leq 35 \mathrm{kV}$ \\
\hline$\Delta U_{\text {stationary }} \geq 3 \%$ & 24 \\
\hline$\Delta U_{\max } \geq 5 \%$ & 24 \\
\hline
\end{tabular}

Table 2. Different scenarios presented.

\begin{tabular}{|c|c|c|}
\hline Scenario & Solar radiation & Production in solar panels \\
\hline Scenario I & $0 \%$ & 0.00 p.u. \\
\hline Scenario II & $10 \%$ & 0.10 p.u. \\
\hline Scenario III & $25 \%$ & 0.25 p.u. \\
\hline
\end{tabular}

The three scenarios presented in Table 2 are used to illustrate the problems regarding passing clouds on summertime, which reduce the power output from the solar panels. Scenario I illustrates the worst case scenario with $0 \%$ production from the solar panels. Further, Scenario II and III illustrates a more realistic Scenario with $10 \%$ and $25 \%$ production from the solar panels when cloudy. Scenario I is not a realistic scenario since there always will be some solar radiation on the solar panels. However, it can be useful for the DSO to take a worst case scenario in consideration for future planning of the grid.

\subsection{Solar data}

Historical solar tracking data are collected from MET Norway. Although they did not have data from Hvaler and recommended Grimstad, which has a similar type of climate as Hvaler. The interest is to study if the changes from sun to clouds will influence the requirements according to FoL $\S 3.4$. If there are more than 24 changes a day where $\Delta U_{\text {stationary }} \geq 3 \%$, the requirements are not met.

Discussions with climate researcher Prof. Elin Lundstad at METs office, lead to the definition of a ratio that represents the change between sun and clouds in minutes. This ratio is set to a switch between sun and clouds each third minute when cloudy. Further, Prof. Lundstad suggested that a typical cloud for Hvaler is the type Congestus, which gives problems for the solar panels due to the thickness of the clouds regarding production.
Consequently, with 51 minutes of sun registered from 10:00 hours to 11:00 hours presented in Table 3. The shift between sun to clouds occurs each third minute during these minutes with passing clouds. These minutes with the passing clouds is the remaining 9 minutes in the hour from 10:00 hours to 11:00 hours.

From the solar tracking data given by MET Norway, a suitable day was chosen to illustrate the problem with more than 24 changes of sun to clouds during a day. Furthermore, the total sun to cloud changes are also given in Table 3, which shows that during $15^{\text {th }}$ June 2018 the change between sun and clouds reaches a number of 70 . That number indicates that if $\Delta U_{\text {stationary }}$ exceeds the limit of $3 \%$ in the simulations and hence the DSO does not meet the requirements during that day.

Table 3. The changes from sun to clouds reached a number of 70, 15. June 2018.

\begin{tabular}{|c|c|c|c|}
\hline Time: & Sun minutes & Passing clouds & Changes \\
\hline 06:00 & 5 & Dawn & 3 \\
\hline 07:00 & 60 & 0 & 0 \\
\hline 08:00 & 60 & 0 & 0 \\
\hline 09:00 & 60 & 0 & 0 \\
\hline $10: 00$ & 51 & 9 & 3 \\
\hline $11: 00$ & 29 & 31 & 10 \\
\hline $12: 00$ & 38 & 22 & 7 \\
\hline $13: 00$ & 44 & 16 & 5 \\
\hline $14: 00$ & 56 & 4 & 1 \\
\hline $15: 00$ & 57 & 3 & 1 \\
\hline $16: 00$ & 60 & 0 & 0 \\
\hline $17: 00$ & 49 & 11 & 4 \\
\hline $18: 00$ & 7 & 53 & 18 \\
\hline $19: 00$ & 17 & 43 & 14 \\
\hline $20: 00$ & 52 & 8 & 3 \\
\hline $21: 00$ & 1 & Dusk & 1 \\
\hline Sum & & & 70 \\
\hline
\end{tabular}

\subsection{The difference between $\Delta U_{\text {stationary }}$ and $\Delta U_{\max }$}

After discussions with Norgesnett, a decision was made to only study $\Delta U_{\text {stationary. This is because NETBAS does }}$ not have the complexity to study $\Delta U_{\max }$, and simulations with $\Delta U_{\max }$ also requires measurements collected from the field. Additionally, the simulations with $\Delta U_{\max }$ require that a time constant must be taken into consideration. This is not done in this paper due to the study of $\Delta U_{\text {stationary }}$ in stationary conditions.

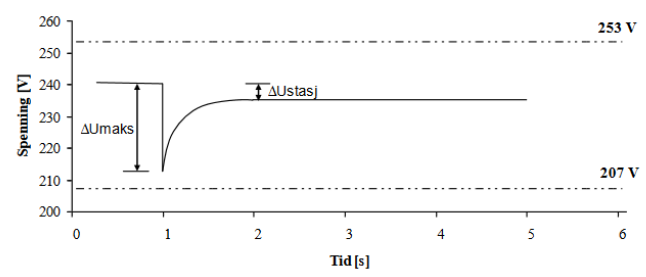

Figure 4. Visualisation of $\Delta U_{\max }$ and $\Delta U_{\text {stationary }}$ (NVE 2018).

In Figure $4 \Delta U_{\max }$ and $\Delta U_{\text {stationary }}$ is presented. $\Delta U_{\max }$ is the maximum change in voltage during the situation, and 
is typically due to startups of larger motors in industrial areas (Lovdata 2004). $\Delta U_{\text {stationary }}$ is the voltage after it has stabilised on a higher, lower or the same level as before the situation arose. In the simulations the voltage is stable on a lower level because of the drop in production at the solar panels due to the clouds.

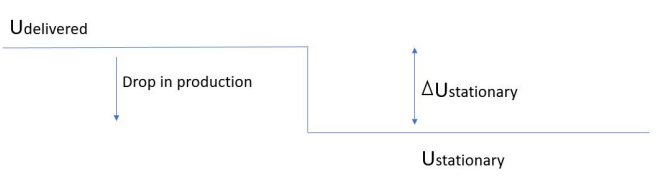

Figure 5. Simplified figure with $\Delta U_{\text {stationary }}$

Figure 5 is a simplified model which illustrates $\Delta U_{\text {stationary. }}$ It shows how a drop in production due to clouds gives a new condition, $U_{\text {stationary }}$. Further, $U_{\text {delivered }}$ is the voltage when the solar panels have full production at the objects. $\Delta U_{\text {stationary }}$ should not exceed the limit of $3 \%$ more frequently than 24 times in a period of 24 hours. Equation (3) is based on Figure 5.

$$
\% U_{\text {stationary }}=\frac{\Delta U_{\text {stationary }}}{U_{\text {delivered }}} \cdot 100 \%
$$

The cabins at Søndre Sandøy are referred to as objects. Furthermore, after discussion with Norgesnett it was decided that the simulations are conducted with regard to normal operating condition with point-analyses in stationary condition. Also, a decision was taken to use the different objects short-circuit performance from NETBAS in comparison with the voltage drop due to the drop in production at the solar panels. Furthermore, to simulate the solar panels at the objects in NETBAS the capacity of the solar panels in $\mathrm{kW}$ are set to a negative value at the objects. This makes the power flow back to the grid and gives a scenario where the objects feed the distribution network, also called prosumers.

The network is tested at cases where an increasing number of objects have solar panels installed. Scenario I, the worst case, is simulated first. If this is not passed then consequently Scenario II and III are simulated as presented in Table 2.

\section{Results}

Here the results from Søndre Sandøy are presented. In the Master's Thesis solar panels from $1 \mathrm{~kW}$ to $3 \mathrm{~kW}$ was studied. In this paper, only the size of $3 \mathrm{~kW}$ is presented in detail since this was the size with most problems for the DSO. Furthermore, all scenarios and cases from Søndre Sandøy are presented in Table 10 and discussed briefly.

\subsection{The test area at Søndre Sandøy}

Søndre Sandøy is located far out in the distribution network and is categorised as a rural area. Søndre Sandøy has low short-circuit performance at the objects. Because of the low short-circuit performance, Søndre Sandøy does not have the prerequisites to deal with a large amount of solar capacity at the objects. There are ten objects and six cases at Søndre Sandøy. Figure 6 shows the ten objects which are studied.

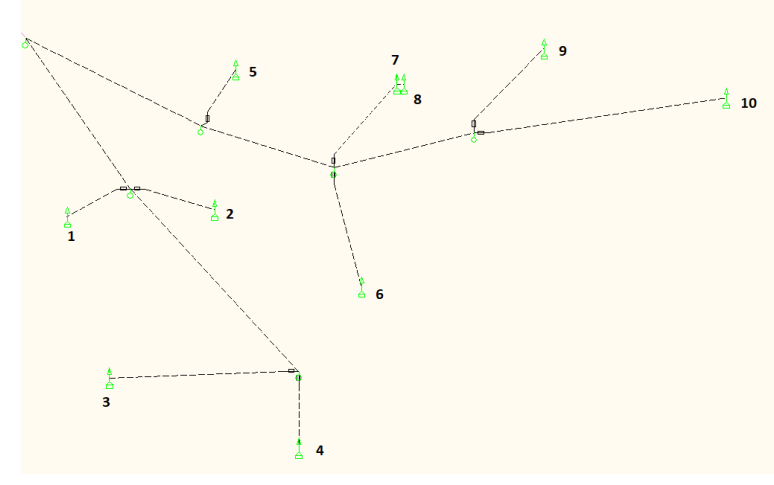

Figure 6. The different objects at Søndre Sandøy.

According to Figure 6, Case 1 is simulated where $\mathrm{Ob}$ ject 5 and 6 have installed solar panels. Further, Case 2 is when Object 7 av 8 have added their solar panels to the network, those objects are also connected to the same line. Further, Object 9 and 10 are added to the network with Case 3 and 4, respectively. They have two cases because of the low short-circuit performance on those objects. Moreover, they are furthest out in the network, which makes them vulnerable to solar panels. Furthermore, down the right at the network, Case 5 is when Object 1 and 2 gets solar panels which are added to the network. And Case 6 is when every object has solar panels installed.

\subsection{Explanation NETBAS simulation tables}

Both, Table 4 and Table 5, are structured in a way that the objects are numbered horizontally $1-10$, and the cases are numbered vertically $1-6$. Table 4 has two colours in the boxes, yellow and blue. Yellow indicates the installed solar capacity at the respective objects in kW. Furthermore, yellow also indicates the object's related voltage, $U_{\text {delivered }}$. The blue colour illustrates the impact of the clouds, which reduces the production in the solar panels to a new value given in $\mathrm{kW}$. Moreover, blue is also the object's new related voltage, $U_{\text {stationary }}$. Furthermore, the white boxes are objects without solar panels, called nonsolar objects. The S-C P is the object's different shortcircuit performance.

Table 5 shows where $\Delta U_{\text {stationary }}$ exceeds the $3 \%$ limit with red boxes, and is calculated as shown in Equation (4).

$\% U_{\text {stationary }}=\frac{\Delta U_{\text {stationary }}}{U_{\text {delivered }}} \cdot 100 \%=\frac{235.2-226.0}{235.2} \cdot 100 \%$

The calculation in Equation (4) illustrates Object 1 at 
Table 4. $3 \mathrm{~kW}$ installed at the objects with $25 \%$ solar production due to clouds.

\begin{tabular}{|l|c|c|c|c|c|c|c|c|c|c|}
\hline & 1 & 2 & 3 & 4 & 5 & 6 & 7 & 8 & 9 & 10 \\
\hline S-C P [MVA] & 0.346 & 0.301 & 0.215 & 0.271 & 0.336 & 0.266 & 0.287 & 0.287 & 0.205 & 0.162 \\
\hline & {$[\mathrm{V}]$} & {$[\mathrm{V}]$} & {$[\mathrm{V}]$} & {$[\mathrm{V}]$} & {$[\mathrm{V}]$} & {$[\mathrm{V}]$} & {$[\mathrm{V}]$} & {$[\mathrm{V}]$} & {$[\mathrm{V}]$} & {$[\mathrm{V}]$} \\
\hline $1: 3 \mathrm{~kW}$ & 219.1 & 218.9 & 218.2 & 218.6 & 219.7 & 219.7 & 219.0 & 219.0 & 218.5 & 217.9 \\
\hline $1: 0.75 \mathrm{~kW}$ & 217.1 & 216.9 & 216.1 & 216.6 & 217.3 & 217.0 & 216.6 & 216.6 & 216.0 & 215.5 \\
\hline $2: 3 \mathrm{~kW}$ & 222.9 & 222.7 & 221.9 & 222.4 & 223.9 & 224.5 & 224.6 & 224.6 & 223.3 & 222.8 \\
\hline $2: 0.75 \mathrm{~kW}$ & 219.2 & 219.0 & 218.2 & 218.7 & 219.6 & 219.6 & 219.7 & 219.7 & 218.7 & 218.2 \\
\cline { 2 - 11 } $3: 3 \mathrm{~kW}$ & 224.6 & 224.4 & 223.7 & 224.1 & 225.8 & 226.7 & 226.8 & 226.8 & 226.9 & 225.9 \\
\hline $3: 0.75 \mathrm{~kW}$ & 220.1 & 219.9 & 219.1 & 219.6 & 220.6 & 220.8 & 220.8 & 220.8 & 220.5 & 219.8 \\
\hline $4: 3 \mathrm{~kW}$ & 226.6 & 226.4 & 225.7 & 226.1 & 228.0 & 229.2 & 229.3 & 229.3 & 230.4 & 231.0 \\
\hline $4: 0.75 \mathrm{~kW}$ & 221.2 & 221.1 & 220.3 & 220.8 & 221.9 & 222.2 & 222.2 & 222.2 & 222.5 & 222.7 \\
\hline $5: 3 \mathrm{~kW}$ & 230.9 & 231.1 & 229.8 & 230.3 & 231.7 & 232.9 & 233.0 & 233.0 & 234.1 & 234.8 \\
\hline $5: 0.75 \mathrm{~kW}$ & 223.5 & 223.6 & 222.5 & 223.0 & 223.9 & 224.2 & 224.2 & 224.2 & 224.5 & 224.7 \\
6: $3 \mathrm{~kW}$ & 235.2 & 235.4 & 236.3 & 235.9 & 235.5 & 236.6 & 236.7 & 236.7 & 237.8 & 238.5 \\
6: $0.75 \mathrm{~kW}$ & 226.0 & 226.0 & 226.3 & 226.1 & 226.0 & 226.3 & 226.4 & 226.4 & 226.6 & 226.8 \\
\hline
\end{tabular}

Case 6 from Table 4. Further, Table 5 represents the answer of the calculation at Object 1 Case 6 . As a result from this, $\% U_{\text {stationary }}$ is larger than $3 \%$, and the requirements states this should not occur more frequently than 24 times a day.

Moreover, all calculations from the simulations in the paper are compared to the sun to cloud changes from $15^{\text {th }}$ June 2018. If the limit of $3 \%$ is exceeded, the requirements are not met during that day.

The different cases indicate which objects have installed solar panels, Case 1 has 1 Object with solar panels and so on. The tables are related to each other, meaning Object 1 in Table 4 is Object 1 in Table 5.

Table 5. $\% U_{\text {stationary }}$ for all the cases regarding Scenario III.

\begin{tabular}{|c|c|c|c|c|c|c|c|c|c|c|}
\hline & 1 & 2 & 3 & 4 & 5 & 6 & 7 & 8 & 9 & 10 \\
\hline $1:$ & $0.91 \%$ & $0.91 \%$ & $0.96 \%$ & $0.91 \%$ & $1.09 \%$ & $1.23 \%$ & $1.09 \%$ & $1.09 \%$ & $1.14 \%$ & $1.10 \%$ \\
\hline $2:$ & $1.65 \%$ & $1.66 \%$ & $1.68 \%$ & $1.66 \%$ & $1.92 \%$ & $2.18 \%$ & $2.18 \%$ & $2.18 \%$ & $2.06 \%$ & $2.06 \%$ \\
\hline $3:$ & $2.00 \%$ & $2.00 \%$ & $2.05 \%$ & $2.00 \%$ & $2.30 \%$ & $2.60 \%$ & $2.64 \%$ & $2.64 \%$ & $2.82 \%$ & $2.70 \%$ \\
\hline $4:$ & $2.38 \%$ & $2.34 \%$ & $2.39 \%$ & $2.34 \%$ & $2.67 \%$ & $3.05 \%$ & $3.09 \%$ & $3.09 \%$ & $3.43 \%$ & $3.59 \%$ \\
\hline $5:$ & $3.20 \%$ & $3.25 \%$ & $3.18 \%$ & $3.17 \%$ & $3.36 \%$ & $3.73 \%$ & $3.78 \%$ & $3.78 \%$ & $4.10 \%$ & $4.30 \%$ \\
\hline $6:$ & $3.91 \%$ & $3.99 \%$ & $4.23 \%$ & $4.15 \%$ & $4.03 \%$ & $4.35 \%$ & $4.35 \%$ & $4.35 \%$ & $4.71 \%$ & $4.91 \%$ \\
\hline
\end{tabular}

\subsection{Study of $3 \mathrm{~kW}$ solar panels at the objects}

In this section Scenario I and Scenario II at Søndre Sandøy with $3 \mathrm{~kW}$ solar panels are presented. Since Scenario III are given in Table 4 and Table 5 in Section 3.2 those tables are not presented again, but Scenario III are discussed referring to Table 4 and Table 5.

\subsubsection{Scenario I}

The largest solar panels that are installed at the objects are $3 \mathrm{~kW}$. The interest is to see how the network responds to this capacity at the different scenarios and cases. For the worst case scenario the voltage drop is presented in Table 6.

Furthermore, Table 7 illustrates how this solar capacity affects $\Delta U_{\text {stationary }}$ where Object 10 at Case 6 reached a percentage of $6.71 \%$. Accordingly, the limit of $3 \%$ is exceeded for Case 3, 4, 5 and 6. Despite this, Case 2 is close to the limit at Object 6, 7 and 8. Moreover, in Case 3,4 , and 5 there are non-solar objects which are affected by the objects with solar panels. Object 10 is a non-solar object in Case 3. In Table 7 the percentage of this object reached $3.71 \%$, which lead to this Object does not pass the requirement. Furthermore, in Case 4 the non-solar ob- ject 1 - 4 exceeds the limit, while in Case 5 the non-solar object 3 and 4 also exceeds the limit. at Case 5 the percentage of non-solar object 3 and 4 increased because of Object 1 and 2 has solar panels installed in Case 5. Table 6 shows the voltage is the same at the objects which have solar panels installed when the production drops to $0 \mathrm{~kW}$. The reason for this could be that Scenario I with $0 \%$ production locally is an unrealistic scenario. Because some solar radiation will pass through the clouds, which generates some production locally at the solar panels. Scenario II and III considers this with production locally when cloudy. However, the results indicate the worst case scenario is not passed. Furthermore, Scenario II follows.

Table 6. $3 \mathrm{~kW}$ installed at the objects with $0 \%$ production due to clouds.

\begin{tabular}{|l|c|c|c|c|c|c|c|c|c|c|}
\hline & 1 & 2 & 3 & 4 & 5 & 6 & 7 & 8 & 9 & 10 \\
\hline S-C P [MVA] & 0.346 & 0.301 & 0.215 & 0.271 & 0.336 & 0.266 & 0.287 & 0.287 & 0.205 & 0.162 \\
\hline & {$[\mathrm{V}]$} & {$[\mathrm{V}]$} & {$[\mathrm{V}]$} & {$[\mathrm{V}]$} & {$[\mathrm{V}]$} & {$[\mathrm{V}]$} & {$[\mathrm{V}]$} & {$[\mathrm{V}]$} & {$[\mathrm{V}]$} & {$[\mathrm{V}]$} \\
\hline 1: $3 \mathrm{~kW}$ & 219.1 & 218.9 & 218.2 & 218.6 & 219.7 & 219.7 & 219.0 & 219.0 & 218.5 & 217.9 \\
\hline $1: 0 \mathrm{~kW}$ & 216.4 & 216.2 & 215.4 & 215.9 & 216.5 & 216.0 & 215.8 & 215.8 & 215.2 & 214.7 \\
\hline $2: 3 \mathrm{~kW}$ & 222.9 & 222.7 & 221.9 & 222.4 & 223.9 & 224.5 & 224.6 & 224.6 & 223.3 & 222.8 \\
\hline $2: 0 \mathrm{~kW}$ & 217.8 & 217.7 & 216.9 & 217.4 & 218.1 & 217.9 & 217.9 & 217.9 & 217.0 & 216.5 \\
\cline { 2 - 10 } $3: 3 \mathrm{~kW}$ & 224.6 & 224.4 & 223.7 & 224.1 & 225.8 & 226.7 & 226.8 & 226.8 & 226.9 & 225.9 \\
\hline $3: 0 \mathrm{~kW}$ & 218.4 & 218.2 & 217.4 & 217.9 & 218.7 & 218.6 & 218.6 & 218.6 & 218.2 & 217.5 \\
\hline $4: 3 \mathrm{~kW}$ & 226.6 & 226.4 & 225.7 & 226.1 & 228.0 & 229.2 & 229.3 & 229.3 & 230.4 & 231.0 \\
\hline $4: 0 \mathrm{~kW}$ & 219.2 & 219.0 & 218.3 & 218.8 & 219.6 & 219.6 & 219.6 & 219.6 & 219.6 & 219.6 \\
\hline $5: 3 \mathrm{~kW}$ & 230.9 & 231.1 & 229.8 & 230.3 & 231.7 & 232.9 & 233.0 & 233.0 & 234.1 & 234.8 \\
\hline $5: 0 \mathrm{~kW}$ & 220.8 & 220.8 & 219.8 & 220.3 & 221.0 & 221.0 & 221.0 & 221.0 & 221.0 & 221.0 \\
\hline 6: $3 \mathrm{~kW}$ & 235.2 & 235.4 & 236.3 & 235.9 & 235.5 & 236.6 & 236.7 & 236.7 & 237.8 & 238.5 \\
\hline 6: $0 \mathrm{~kW}$ & 222.5 & 222.5 & 222.5 & 222.5 & 222.5 & 222.5 & 222.5 & 222.5 & 222.5 & 222.5 \\
\hline
\end{tabular}

Table 7. $\% U_{\text {stationary }}$ for all the cases regarding Scenario I.

\begin{tabular}{|c|c|c|c|c|c|c|c|c|c|c|}
\hline & 1 & 2 & 3 & 4 & 5 & 6 & 7 & 8 & 9 & 10 \\
\hline $1:$ & $1.23 \%$ & $1.23 \%$ & $1.28 \%$ & $1.23 \%$ & $1.45 \%$ & $1.68 \%$ & $1.46 \%$ & $1.46 \%$ & $1.51 \%$ & $1.47 \%$ \\
\hline $2:$ & $2.28 \%$ & $2.24 \%$ & $2.25 \%$ & $2.24 \%$ & $2.60 \%$ & $2.94 \%$ & $2.98 \%$ & $2.98 \%$ & $2.82 \%$ & $2.83 \%$ \\
\hline $3:$ & $2.76 \%$ & $2.76 \%$ & $2.81 \%$ & $2.76 \%$ & $3.14 \%$ & $3.57 \%$ & $3.61 \%$ & $3.61 \%$ & $3.83 \%$ & $3.71 \%$ \\
\hline $4:$ & $3.27 \%$ & $3.27 \%$ & $3.29 \%$ & $3.23 \%$ & $3.68 \%$ & $4.19 \%$ & $4.23 \%$ & $4.23 \%$ & $4.69 \%$ & $4.94 \%$ \\
\hline $5:$ & $4.37 \%$ & $4.46 \%$ & $4.35 \%$ & $4.34 \%$ & $4.61 \%$ & $5.11 \%$ & $5.15 \%$ & $5.15 \%$ & $5.60 \%$ & $5.88 \%$ \\
\hline $6:$ & $5.40 \%$ & $5.48 \%$ & $5.84 \%$ & $5.68 \%$ & $5.52 \%$ & $5.96 \%$ & $6.00 \%$ & $6.00 \%$ & $6.44 \%$ & $6.71 \%$ \\
\hline
\end{tabular}

\subsubsection{Scenario II}

Table 8 shows that the voltage drop is lower which is because of the $10 \%$ local production at the customer when cloudy. Table 9 indicates that for Scenario II the $\Delta U_{\text {stationary }}$ is still too high for Case 3, 4, 5 and 6, despite the percentage being evenly a bit lower in all cases. As seen in this scenario the problems start at Case 3, when 5 Objects have installed solar panels. The highest percentage at Object 10 in Case 6 has decreased to $5.95 \%$, but also in this Scenario all objects at Case 5 and 6 have a too high percentage. This scenario has fewer non-solar objects which exceed the limit due to the lower voltage drop because of the $10 \%$ power production from the solar panels. 
Table 8. $3 \mathrm{~kW}$ installed at the objects with $10 \%$ solar production due to clouds.

\begin{tabular}{|l|c|c|c|c|c|c|c|c|c|c|}
\hline & 1 & 2 & 3 & 4 & 5 & 6 & 7 & 8 & 9 & 10 \\
\hline S-C P [MVA] & 0.346 & 0.301 & 0.215 & 0.271 & 0.336 & 0.266 & 0.287 & 0.287 & 0.205 & 0.162 \\
\hline & {$[\mathrm{V}]$} & {$[\mathrm{V}]$} & {$[\mathrm{V}]$} & {$[\mathrm{V}]$} & {$[\mathrm{V}]$} & {$[\mathrm{V}]$} & {$[\mathrm{V}]$} & {$[\mathrm{V}]$} & {$[\mathrm{V}]$} & {$[\mathrm{V}]$} \\
\hline $1: 3 \mathrm{~kW}$ & 219.1 & 218.9 & 218.2 & 218.6 & 219.7 & 219.7 & 219.0 & 219.0 & 218.5 & 217.9 \\
\hline $1: 0.3 \mathrm{~kW}$ & 216.6 & 216.5 & 215.7 & 216.2 & 216.8 & 216.4 & 216.1 & 216.1 & 215.5 & 215.0 \\
\hline $2: 3 \mathrm{~kW}$ & 222.9 & 222.7 & 221.9 & 222.4 & 223.9 & 224.5 & 224.6 & 224.6 & 223.3 & 222.8 \\
\hline $2: 0.3 \mathrm{~kW}$ & 218.4 & 218.2 & 217.4 & 217.9 & 218.7 & 218.6 & 218.6 & 218.6 & 217.7 & 217.2 \\
\cline { 2 - 11 } $3: 3 \mathrm{~kW}$ & 224.6 & 224.4 & 223.7 & 224.1 & 225.8 & 226.7 & 226.8 & 226.8 & 226.9 & 225.9 \\
\hline $3: 0.3 \mathrm{~kW}$ & 219.1 & 218.9 & 218.1 & 218.6 & 219.5 & 219.5 & 219.5 & 219.5 & 219.1 & 218.4 \\
\hline $4: 3 \mathrm{~kW}$ & 226.6 & 226.4 & 225.7 & 226.1 & 228.0 & 229.2 & 229.3 & 229.3 & 230.4 & 231.0 \\
\hline $4: 0.3 \mathrm{~kW}$ & 220.0 & 219.9 & 219.1 & 219.6 & 220.5 & 220.7 & 220.7 & 220.8 & 220.8 & 220.9 \\
\hline $5: 3 \mathrm{~kW}$ & 230.9 & 231.1 & 229.8 & 230.3 & 231.7 & 232.9 & 233.0 & 233.0 & 234.1 & 234.8 \\
\hline $5: 0.3 \mathrm{~kW}$ & 221.9 & 221.9 & 220.9 & 221.4 & 221.1 & 222.3 & 222.3 & 222.3 & 222.4 & 222.5 \\
$6: 3 \mathrm{~kW}$ & 235.2 & 235.4 & 236.3 & 235.9 & 235.5 & 236.6 & 236.7 & 236.7 & 237.8 & 238.5 \\
6: $0.3 \mathrm{~kW}$ & 223.9 & 223.9 & 224.0 & 224.0 & 223.9 & 224.1 & 224.1 & 224.1 & 224.2 & 224.3 \\
\hline
\end{tabular}

Table 9. $\% U_{\text {stationary }}$ for all the cases regarding Scenario II.

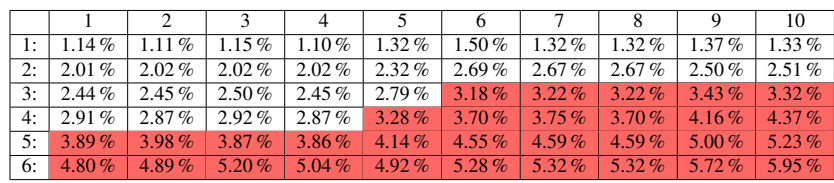

\subsubsection{Scenario III}

The results from Scenario III are given from Table 4 and Table 5. Also this scenario shows that $\Delta U_{\text {stationary }}$ is too high for Case 4, 5 and 6 according to Table 5, despite the percentage being lower in all cases due to the lower voltage drop. Also 5 of 10 objects pass Case 4 . However, the scenarios indicate that a capacity of $3 \mathrm{~kW}$ solar panels is too much for the network. The $\Delta U_{\text {stationary }}$ is too high for Case 4, 5 and 6 according to Table 5. Also 5 of 10 objects pass Case 4. Further, the non-solar objects that exceed the limit are only spotted in Case 5 at Object 3 and 4 . The reason for this is because of this is the easiest scenario to pass due to the lower voltage drop at the solar panels. However, the scenarios indicate that a capacity of $3 \mathrm{~kW}$ solar panels are too much for the network.

\section{Discussion}

In Table 10 all the cases and scenarios at Søndre Sandøy are presented with a different size of solar panels at the objects.

Table 10. The different scenarios and cases at Søndre Sandøy.

\begin{tabular}{|l|l|l|l|l|l|l|l|l|l|l|l|l|l|}
\hline & $1 \mathrm{~kW}$ & \multicolumn{1}{|c|}{$2 \mathrm{~kW}$} & \multicolumn{7}{|c|}{$3 \mathrm{~kW}$} \\
\hline Scenario I & $1-6$ & 1 & 2 & 3 & 4 & 5 & 6 & 1 & 2 & 3 & 4 & 5 & 6 \\
\hline Scenario II & $1-6$ & 1 & 2 & 3 & 4 & 5 & 6 & 1 & 2 & 3 & 4 & 5 & 6 \\
\hline Scenario III & $1-6$ & 1 & 2 & 3 & 4 & 5 & 6 & 1 & 2 & 3 & 4 & 5 & 6 \\
\hline
\end{tabular}

Søndre Sandøy had challenges with the installed solar panels in the network. With $1 \mathrm{~kW}$ installed solar panels at the objects the requirements were met for all scenarios from Case $1-6$ according to Table 10 and did not indicate any problem for the DSO. Also shown in Table 10 the main challenges occur with $2 \mathrm{~kW}$ and $3 \mathrm{~kW}$ solar panels.

With $2 \mathrm{~kW}$ solar panels in Scenario II and III the requirements were held up to Case 3 and Case 4, respectively, as shown in Table 10. In Scenario I two non-solar objects exceeded the limit of $3 \%$ at Case 5 (Marius Salen 2019). This clarifies the impact clouds have on solar panels on a weak grid since the change in production caused by the passing clouds also has an impact on the customers without solar panels.

For the $3 \mathrm{~kW}$ solar panels only Case 1 and 2 passed Scenario I and Scenario II. Besides this, the percentage of $\Delta U_{\text {stationary }}$ is high for all objects at the different cases in the two scenarios. Furthermore, Scenario III for $3 \mathrm{~kW}$ exceed the limit for Case $4-6$, and the $\Delta U_{\text {stationary }}$ is still quite high with a maximum of $4.91 \%$ at Case 6 , Object 10 seen from Table 5. Also, there where non-solar objects which got affected by the objects with solar panels in all of the scenarios.

As a result of the previous simulations, the DSO should be aware of an increase in solar capacity at this part of the network in Søndre Sandøy. Especially with solar panels of $2 \mathrm{~kW}$ and $3 \mathrm{~kW}$, as this can lead to challenges regarding the requirements at $\S 3.4$ in FoL. The number of prosumers has increased throughout the years (Dinside 2019). Since Hvaler is an island with many prosumers compared to the population, the cases in the different scenarios illustrated are likely to occur. From this, the DSO can take the results from the simulations in consideration when planning for future grid development.

\section{Conclusion}

In the scenarios where Søndre Sandøy had solar panels installed at the objects the related voltage $U_{\text {delivered }}$ increased. In the simulations no problems where found with $1 \mathrm{~kW}$ installed solar panels at the objects regarding FoL. Also, the simulations revealed that Søndre Sandøy had challenges when the objects had $2 \mathrm{~kW}$ and $3 \mathrm{~kW}$ solar panels installed. This is due to a weak grid with low shortcircuit performance at the objects.

Furthermore, the simulations show that passing clouds make a significant impact on the solar panels due to the voltage drop at the customer. Especially when a lot of objects have installed solar panels. This will lead to the requirements in FoL are not met in some cases. Also found from the simulation at Søndre Sandøy was that the nonsolar objects were affected by the objects with solar panels when the size of $2 \mathrm{~kW}$ and $3 \mathrm{~kW}$ was simulated.

\section{Further work}

In this paper only analysis for $\Delta U_{\text {stationary }}$ were conducted. A recommendation for further work is to study scenarios with $\Delta U_{\max }$ and to see how this responds to the requirements from FoL $\S 3.4$. Simulations with $\Delta U_{\max }$ require measurements from the field to compare with the simulations. To simulate the $\Delta U_{\max }$ the dynamic power system simulation software like PowerFactory can be used. This software has a higher complexity to simulations compared to NETBAS, and that is required for the study of $\Delta U_{\max }$.

Also a recommendation for further study is to use $10 \%$ as a worst case scenario. The reason for this is to get a 
worst case which is more likely to occur, since $0 \%$ production is not a realistic scenario because there always will be some solar radiation that passes through the clouds. Also, to get even more realistic scenarios, measures on a PV-panel regarding the voltage drop due to the clouds can be taken.

\section{References}

Cheiw Yun Lau, Chin Kim Gan, Chin Ho Tie, Kyairul Azmi Baharin, and Mohamad Fani Sulaima. Passing-cloud Effects of Solar Photovoltaic System on Distribution Network Voltages, 2015.

Christian Rendall Olsen. Economic feasibility analysis of microgrids in Norway: an application of HOMER Pro. MA thesis. Campus Ås: NMBU, 2018.

Dinside. Hva er en plusskunde? URL: https : // www . dinside. no/okonomi / na-skal-detbli-enklere-a-bli-eget-stromselskap/ 70850821 (visited on 04/12/2019), 2019.

Camilla Seland Ellefsen. Grid Connected PV and the Risk of Overvoltages. MA thesis. Grimstad: Universitetet i Agder, 2014.

Lovdata. Forskrift om kontroll av nettvirksomhet, \$3.4. URL: https: / / lovdata. no/dokument / SF / forskrift/2004-11-30-1557 (visited on 02/ 17/2019), 2004.

M.A. Mahmud, M.J. Hossain, and H.R. Pota. Analysis of Voltage Rise Effect on Distribution Network with Distributed Generation, 2011.

Marius Salen. Impact of distributed generatin in the distribution network at the end-customer. MA thesis. Porsgrunn: USN, 2019.

NVE. Veileder til leveringskvalitetforskriften. In POWEL,POWEL NETBAS takes you closer to reality improved support by step-by-step building. URL:

https://www. powel.com/about/feature_ stories / powel - netbas - tar - deg narmere - virkeligheten -- forbedret stotte-ved-stegvis-bygging/ (visited on 02/11/2019), 2018.

Wikipedia. Hvaler (kommune). URL: https : / / no. wikipedia . org / wiki / Hvaler _ (kommune) (visited on 01/06/2019), 2019.

Wilson Rickerson. Residental prosumers - Drivers and policy options, 2014. 